\title{
Radiated Ultrashort High-Power Electromagnetic Pulses Induce ATP Release in B16F10 Murine Melanoma Cells
}

\author{
Sabrina Macaire ${ }^{1}$, Alexandre Catrain ${ }^{1}$, Stéphane Tortel ${ }^{1}$, Jean-Christophe Joly ${ }^{1}$, \\ Sébastien Girard ${ }^{2,3}$, Pierre Bonnet ${ }^{2,3}$, Alain Vian ${ }^{4}$ \\ ${ }^{1}$ CEA, DAM, Gramat, France \\ ${ }^{2}$ Institut Pascal, Université Blaise Pascal, Clermont-Ferrand, France \\ ${ }^{3} \mathrm{CNRS}$, UMR 6602, Aubière, France \\ ${ }^{4}$ ARCH-E. Université d'Angers, UMR 1345 IRHS, Angers, France \\ Email: pierre.bonnet@lasmea.univ-bpclermont.fr
}

Received 3 March 2015; accepted 16 March 2015; published 19 March 2015

Copyright (C) 2015 by authors and Scientific Research Publishing Inc.

This work is licensed under the Creative Commons Attribution International License (CC BY).

http://creativecommons.org/licenses/by/4.0/

c) (i) Open Access

\begin{abstract}
Ultrawideband electromagnetic pulses with high amplitude and short duration are reported to affect several aspects of cell physiology. They are usually delivered to the living material through electrodes in small dedicated chambers. Here we showed, using a totally different experimental setup, that radiated EM pulses illuminating the living material through a specialized antenna (without any direct contact) are able to trigger a rapid release of ATP in cultured murine cells that was concomitant with a drop of intracellular AEC. Despite this rapid and strong response, we found that cell viability and clonogenicity were only slightly affected by the EMF exposure.
\end{abstract}

Keywords

Radiated Electromagnetic Pulses, Koshelev Antenna, eATP, Cell Viability

\section{Introduction}

Electromagnetic-pulsed radiation is nowadays increasingly used for diverse military [1] and civilian (mainly medical) purposes [2], including cancer therapy and chronic pain treatment [3]-[5]. This technology is also giving rise to new kind of radar imagery both in the medical and military area [6], including generation of electromagnetic weapons based on high power ultrashort (nanosecond) electromagnetic pulses, commonly designated as Ultra-WideBand electromagnetic radiation (UWB). Their specific properties, namely a very high amplitude 
(several dozens of $\mathrm{kV} \cdot \mathrm{m}^{-1}$ ), a complex temporal signature and an ultrashort (nanosecond) duration, make them difficult to produce and little is known on their overall possible effects on living organism (including human). It is worth noting that the very low energy transfers from the electromagnetic waves to the living material, mainly due to the ultrashort duration, only allows for non-thermal effects to arise [7].

The most common method used to apply such electromagnetic radiation to living organisms consists of a direct injection of pulsed electric field using a small chamber surrounded by metallic electrodes [8]. This allows an effective technical set-up and an excellent control and transfer of the electromagnetic waves to the living cells or organisms that are maintained in an appropriate liquid medium. Indeed, numerous physiological modifications, including changes in signaling pathways, were reported after exposing cell or living tissues to various kinds of pulsed electromagnetic fields. The exposure could lead to DNA damage and cell viability issues [9] or cell apoptosis in human cells [10]. A cytosolic calcium increase followed by caspase activation arose in human lymphocytes after nanosecond pulse [11]. Exposure of pre-neoplastic CL-S1 mammary epithelial cells to $18 \mathrm{kV} \cdot \mathrm{m}^{-1}$, $1 \mathrm{kHz}$ repetition rate, 10 ns pulse during 4 - 6 h promote their proliferation through the mitogen-activated protein kinase (MAPK) signaling pathway [12]. The mitogenic activity in AML-12 Mouse Hepatocytes was increased after $2 \mathrm{~h}$ exposure to UWB radiations (pulse width of $10 \mathrm{~ns}$, repetition rate of $1 \mathrm{kHz}$, amplitude of 5 - 20 $\mathrm{kV} \cdot \mathrm{m}^{-1}$ ) through the induction of cyclin A [13]. These physiological alterations are mainly understood as being the consequence of cell membrane permeabilization. Indeed, it is well known that electromagnetic pulses provided to biological samples using electrodes in a small chamber evoke the formation of pores both in the plasmalemma [14] [15] and in the nuclear membrane [16]. Experiments demonstrated that the pores were created very rapidly (within a few nano seconds) and that their number, conductance and size were proportional to the pulsed electric strength [17]-[19]. The increase in membrane conductance allows external ionic and polar molecules, normally efficiently blocked by the highly hydrophobic living membranes, to enter or exit the cell [20] [18], especially as the resealing of the cell membrane is a slow process that lasts for minutes [21]-[23]. Adenosine tri-phosphate (ATP) is a highly polar intracellular energy-related and signal molecule that is commonly used to report pore formation in the plasma membrane [24] because of the very low membrane permeability toward ATP. Thus, the so-called extracellular ATP (eATP) might appear as a major physiological event [25] especially in the context of electromagnetic or electric field stimulation [24] [26]. Aside from the formation of pores, an increasing number of reports highlight the existence of stretch or mechano-sensitive ATP-channels that could be involved in ATP release and indirect evidences suggest their involvement in cells responses to UWB exposure [27].

In contrast to the electrode-based electromagnetic pulses injection, the use of radiating antennas to perform, at a distance, stimulations of the biological samples (not by direct contact of electrodes with the culture medium) received only little attention. This kind of exposure is however quite commonly encountered in various kinds of environments, both in civilian and military areas. Very little information is indeed available at present time to decipher if living organisms 1) actually respond to radiated UWB radiation and 2) if these responses behave similarly or differently from those observed after direct UWB surge application by immersed electrodes. Our aim in the present work was to determine if high power UWB electromagnetic waves emitted by a Koshelev antenna induce physiological changes in cultured animal cells. Here we report evidences showing that radiated UWB electromagnetic pulses cause a rapid and important ATP release, significantly diminished cell clonogenicity, but only slightly affects overall cell viability.

\section{Material and Methods}

\subsection{Cell Culture}

Murine melanoma cells (B16F10) were maintained $\left(37^{\circ} \mathrm{C}, 5 \% \mathrm{CO}_{2}\right)$ in Dulbecco's modified Eagle's medium (DMEM) high glucose containing $10 \%$ heat inactivated FBS and supplemented with penicillin $\left(100 \mathrm{U} \cdot \mathrm{mL}^{-1}\right)$, streptomycin $\left(100 \mu \mathrm{g} \cdot \mathrm{mL}^{-1}\right)$ and L-glutamine $(2 \mathrm{mM})$. The cells were transferred on fresh medium every 2 days.

\subsection{Electromagnetic Stimulation Design and Exposure Experiments}

All radiation tests were performed in an anechoic chamber. A high pulsed power generator combined with an ad hoc antenna was used for the generation of high-power electromagnetic waves. Figure 1(a) summarizes the experimental set-up. A signal was first shaped using a high voltage pulse generator (Kentech model PBG5, with a 
250 ps rise-time measured from $10 \%$ to $90 \%$ of the amplitude value, a 2.4 ns duration measured at $50 \%$ of the peak value, and a $2 \mathrm{kV}$ peak value for a $50 \Omega$ load). Then, a Koshelev-like ultra wide band antenna [28] radiated this transient electromagnetic signal in the form of repetitive pulses (100 Hz pulse repetition frequency). This compact antenna $\left(38.5 \times 30 \times 30 \mathrm{~cm}^{3}\right)$ has been designed and optimized by CISTEME [29] to widen the bandwidth from $200 \mathrm{MHz}$ to $2 \mathrm{GHz}$. The biological samples were located in the antenna heart between the two radiating elements (Figure 1(b)). At the same position but in the absence of the biological samples, the ultra wide band EM field was measured with an electric field surface sensor made of a SMA connector whose metallic shield was connected to the antenna and the inner conductor was introduced in the antenna. The length of the inner conductor is very short (less than $1 \mathrm{~mm}$ ) so that it is considered as a non-intrusive derivative sensor with a very high bandwidth (more than 10's of GHz): $\quad E_{\text {sensor (in V/m) }}(t)=K \int V_{\text {sensor (in V) }}(t) \mathrm{d} t . K$ is obtained from calibration using a network analyzer. The signal was monitored with a numerical oscilloscope (Lecroy-Waverunner, model $640 \mathrm{Zi}$, Figure 2(a)). The electric field radiated by the antenna was also simulated and verified using the temporal solver of CST Microwave Studio ${ }^{\circledR}$ (Figure 2(b)).

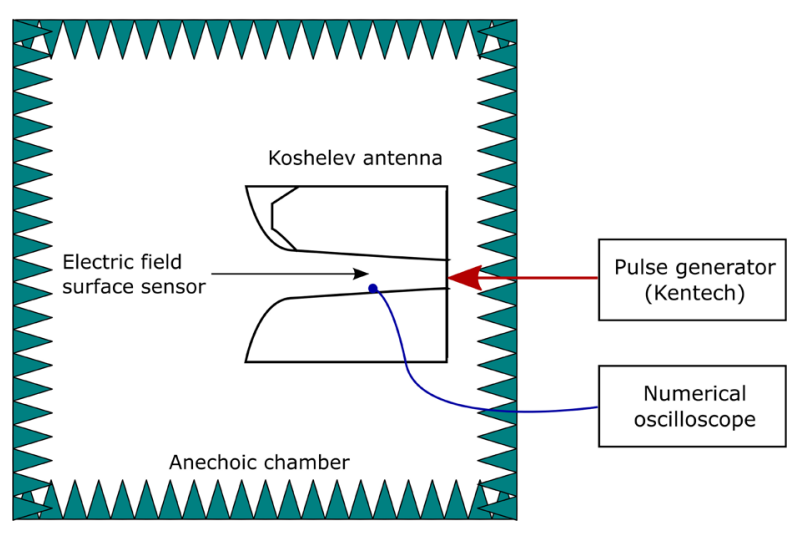

(a)

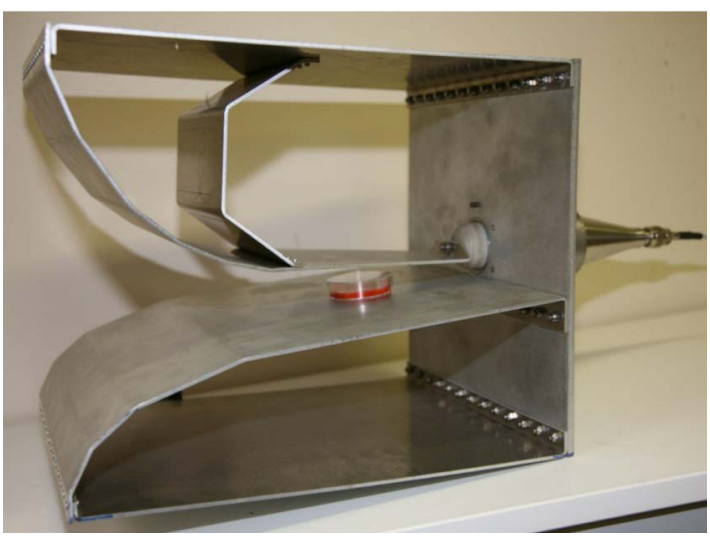

(b)

Figure 1. Experimental set-up. (a) General set-up. This scheme illustrates the Koshelev-like antenna powered by a Kentech generator and placed in an anechoic chamber in order to suppress interactions with undesired electromagnetic waves. A surface electric field sensor coupled to a numeric oscilloscope (Lecroy-Waverunner, model $640 \mathrm{Zi}$ ) measured the radiated electric field. (b) Koshelev antenna detail showing the position of the Petri dish containing the B16F10 murine melanoma cells.

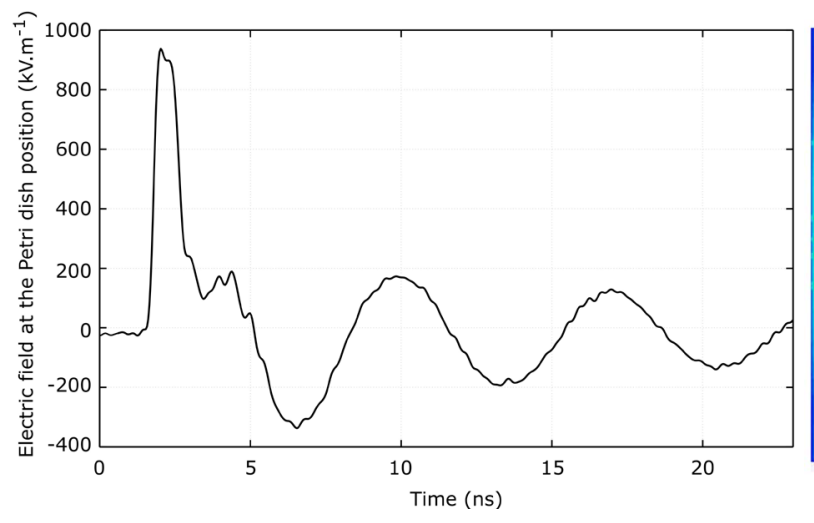

(a)

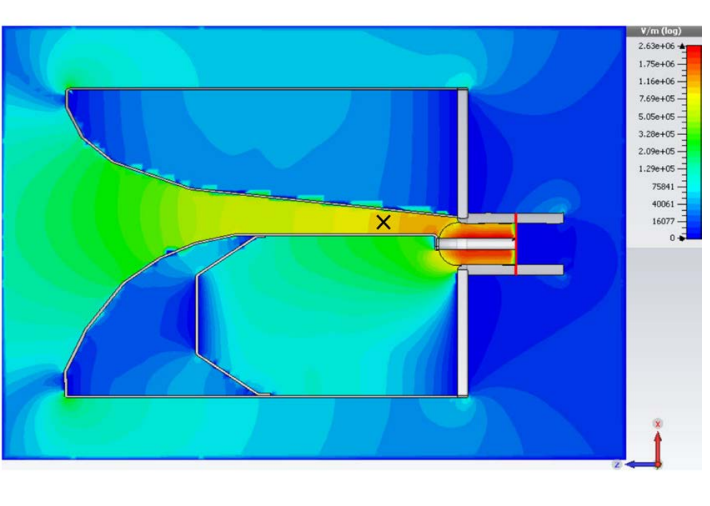

(b)

Figure 2. Radiated electric field characteristics. (a) Wave form of the transient radiated electric field. The signal was measured at the Petri dish location, in absence of the Petri dish. The main peak value was measured at $930 \mathrm{kV} \cdot \mathrm{m}^{-1}$. The rise-time is $0.25 \mathrm{~ns}$, corresponding to an UWB frequency spectrum [15]. (b) Spatial electric field distribution in the Koshelev-like antenna in absence of the Petri dish. This numerical simulation performed with CST Microwave Studio ${ }^{\circledR}$ shows that the electric field amplitude is maximal at the antenna center, where the biological samples are located (cross marker). Numerical peak value is $845 \mathrm{kV} \cdot \mathrm{m}^{-1}$, for a vertical distance between the two radiating element of $2.8 \mathrm{~cm}$. 
We exposed the B16F10 cells plated in a $3 \mathrm{~cm}$ Petri dish in triplicate at room temperature to 60,000 electromagnetic pulses (2 distinct 5 min 30,000 pulses each, peak-intensity $930 \mathrm{kV} \cdot \mathrm{m}^{-1}$, separated by 20 min interval, with $100 \mathrm{~Hz}$ pulse repetition frequency). The temperature of the culture medium was monitored with an optic fiber thermometer (Luxtron 812) and found to be not affected by the electromagnetic pulses. Shame (i.e. control) experiments were done exactly the same way, except that the Kentech amplifier was turned-off.

\subsection{Measurement of Extracellular ATP (eATP) Concentration}

ATP release in the culture medium was measured using the ATP bioluminescence assay kit HS II (Roche Diagnostic) as described by the manufacturer. Briefly, $5 \times 10^{5}$ cells were subjected to the electromagnetic stimulation in the Petri dish and $110 \mu \mathrm{L}$ of the suspension were collected and centrifuged. The supernatant (50 $\mu l)$ was used for ATP determination immediately after the addition of an equal volume of Luciferin/luciferase mixture. The bioluminescence was measured in opaque 96-wells plate to avoid optical leaks using a Berthold LB-96V microplate luminometer. The ATP concentration in sample was determined using a standard curve made with 10-fold serial dilutions of ATP and expressed as relative to the eATP concentration of the control (i.e. non exposed) sample. A positive hypotonic stress control, known to cause a massive ATP release, was performing by adding 1 $\mathrm{mL}$ of deionized sterile water to the Petri-Dish. The adenylate energy charge (AEC) was determined as previously described [30] and calculated with the following equation:

$$
\mathrm{AEC}=([\mathrm{ATP}]+1 / 2[\mathrm{ADP}]) /([\mathrm{ATP}]+[\mathrm{ADP}]+[\mathrm{AMP}])
$$

\subsection{Clonogenic and Viability Assays}

Clonogenic capacity was determined in Petri-dishes seeded with $5 \times 10^{3}$ cells in DMEM, 10\% FBS in the presence (or absence) of 500 pM of the P2X receptor agonist BzATP. After $24 \mathrm{~h}$, the cells were exposed to electromagnetic pulses and allowed to growth for 5 days. The colonies were counted after cell staining with crystal violet. The cell viability was evaluated in Petri-dishes seeded with $3 \times 10^{5}$ cells in DMEM, 10\% FBS. The cells were exposed $24 \mathrm{~h}$ later to the electromagnetic pulses and the surviving cells counted $48 \mathrm{~h}$ later after trypan blue staining.

\section{Results}

\subsection{Ultra Wide Band Electromagnetic Field Characteristics}

The measured waveform of the transient electric field at the petri dish location and numerical simulation of electromagnetic field values are reported in Figure 2. The measured main peak signal amplitude reached 930 $\mathrm{kV} \cdot \mathrm{m}^{-1}$ with an apparent rise-time of $0.25 \mathrm{~ns}$ (measured from $10 \%$ to $90 \%$ of the amplitude value, Figure 2 (a)). Very similar results were obtained from numerical simulations of the exposure, both for the rise-time and the peak amplitude $\left(841 \mathrm{kV} \cdot \mathrm{m}^{-1}\right.$, Figure 2(b)). Furthermore, the spatial distribution of the EM field amplitude shows that this latter reached the maximum in the neighborhood where the Petri dish has been placed for the stimulations (Figure 2(b)).

\subsection{Biological Responses of B16F10 Cells}

The overall viability of B16F10 cells was not affected by the radiated electromagnetic pulses (Table 1). The percentage of living cells was high ( $>97 \%$ ) in the control (unstimulated cells) and was not modified by the UWB radiation exposure, whatever the treatment configuration (1 set of 60,000 pulses or 2 sets of 30,000 pulses each). This result also indicated that the different manipulations of the Petri-dishes that were required for the UWB radiation exposure were not an issue for the B16F10 cells.

As expected, the eATP concentration was low in the culture medium of B16F10 cells and readily increased after the application of the radiated electromagnetic pulses (Figure 3(a)). The concentration more than doubled 2.5 min after the treatment to reach a maximum increase (about 5.5-fold) after 15 min, and started to decline after 30 min, where it was about 4-fold the level observed in the control condition. While this increase in ATP in the culture medium was strong and rapid, it was about 3-fold lower than the positive (hypotonic stress) control that caused an over 15-fold increase only $5 \mathrm{~min}$ after the treatment (Figure 3(b)), suggesting that the ATP 
Table 1. Clonogenicity, cell survival and adenylate energy charge after exposure to UWB radiation. Clonogenicity was determined in control cells (sham), in the presence of bzATP and after exposure to UWB radiation (2 sets of 30,000 pulses or a single set of 60,000 pulses). Cell viability and Adenylate Energy Charge (AEC) was measured in control (sham) and after ex-posure to UWB radiation (2 sets of 30,000 pulses or a single set of 60,000 pulses). Each value is the mean of three independent experiments \pm se.

\begin{tabular}{|c|c|c|c|c|}
\hline \multicolumn{5}{|c|}{ A. Clonogenicity } \\
\hline \multirow{2}{*}{ Colonies } & Sham & Sham + bzATP & $2 \times 30,000$ pulses & 60,000 pulses \\
\hline & $100 \pm 4.69$ & $67.72 \pm 4.70$ & $77.20 \pm 5.32$ & $83.70 \pm 5.63$ \\
\hline \multicolumn{5}{|c|}{ B. Cell viability } \\
\hline & Sham & $2 \times 30,000$ pulses & 60,000 pulses & \\
\hline Alive & $100 \pm 3.03$ & $101.70 \pm 3.50$ & $108.77 \pm 3.51$ & \\
\hline Dead & $2.42 \pm 0.35$ & $3.16 \pm 0.61$ & $3.33 \pm 0.17$ & \\
\hline \multicolumn{5}{|l|}{ C. AEC } \\
\hline & Sham & $2 \times 30,000$ pulses & & \\
\hline & $0.37 \pm 0.067$ & $0.58 \pm 0.026$ & & \\
\hline
\end{tabular}

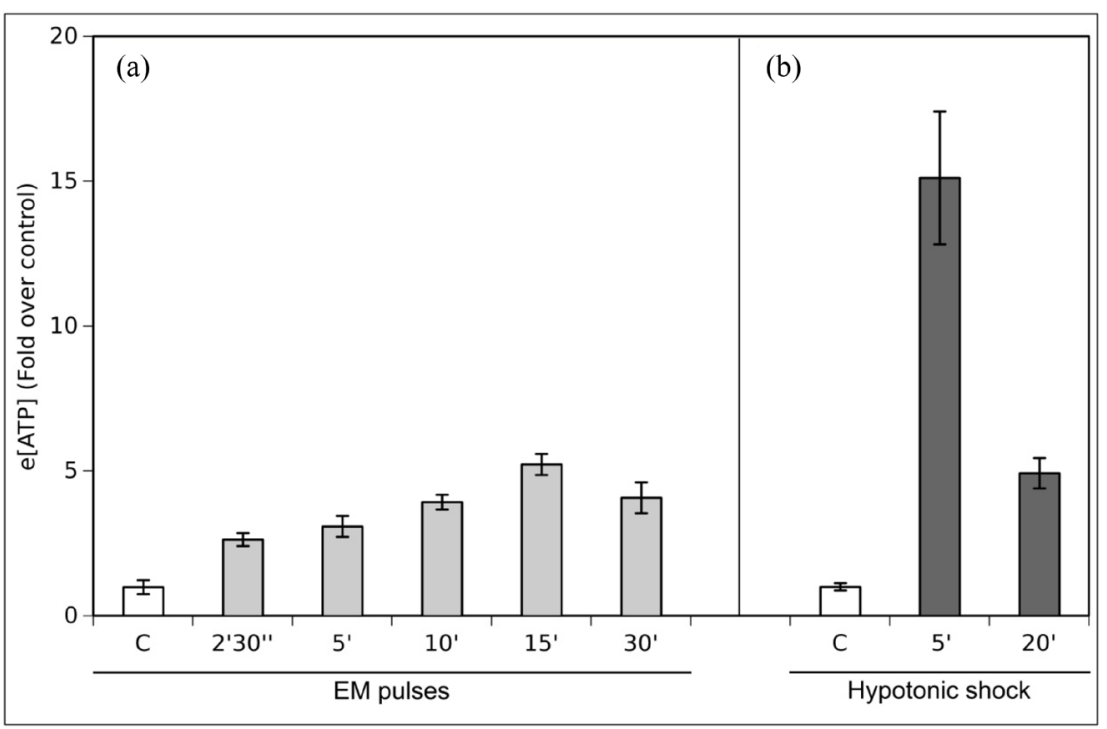

Figure 3. Extracellular ATP after UWB radiation exposure and hypotonic shock. (a) Extracellular ATP (eATP) concentration after UWB radiation exposure $(2 \times 30,000$ pulses, $930 \mathrm{kV} \cdot \mathrm{m}^{-1}, 100 \mathrm{~Hz}$ pulse repetition frequency) expressed relatively to the control, unexposed sample taken as base 1. (b) ATP released after hypotonic shock. Each value is the mean of three independent experiments \pm se.

externalization in response to UWB radiation is implying only part of the available cellular ATP. Concomitantly, intracellular ATP strongly decreased from 3.8 to 1.6 pmole $\cdot \mathrm{\mu g}^{-1}$ protein $15 \mathrm{~min}$ after the application of electromagnetic pulses (Figure 4), confirming the intracellular origin of the eATP and suggesting that its increase mobilized over the half of the available ATP pool of the cells. Indeed, the adenylate energy charge, measured to a standard value of 0.73 in the control cells drop to the mean low value of $0.5815 \mathrm{~min}$ after the treatment in exposed samples (Table 1), confirming a strong effect of radiating UWB radiation pulses toward the energetic status of the cells.

The clonogenic capacity of B16F10 cells was significantly affected by electromagnetic pulses (Table 1) that caused about 20\% drop, whatever the treatment configuration ( 1 set of 60,000 pulses or 2 sets of 30,000 pulses 


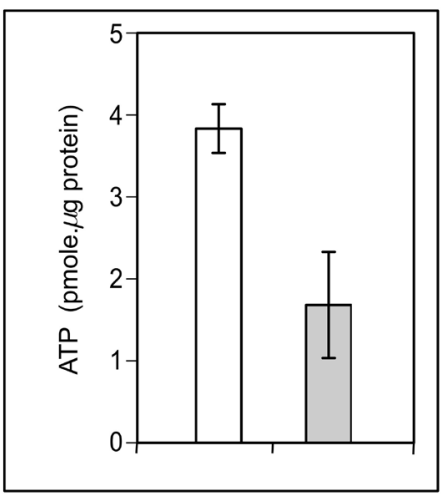

Figure 4. Intracellular ATP after UWB radiation exposure. Intracellular ATP (pmol ATP $\mu \mathrm{g}^{-1}$ protein) after UWB radiation exposure $\left(2 \times 30,000\right.$ pulses, $930 \mathrm{kV} \cdot \mathrm{m}^{-1}, 100 \mathrm{~Hz}$ pulse repetition frequency). Mean of three independent experiments \pm se.

each). This result was similar to the clonogenic capacity decrease observed in the presence of $500 \mathrm{pM}$ of the ATP agonist BzATP, suggesting that eATP interfere with the purinergic P2X7 receptors and thus is susceptible to act, outside of the cell, as a physiologically active molecule.

\section{Discussion}

The direct injection of UWB electromagnetic pulses using immersed electrodes in direct contact with the culture medium in small specialized designed cuvette is widely used to study their biological effects on living material [11]. However, exposure of living organisms in an open volume (where no direct contact of electrodes could be achieve) remains frequent both in civilian and military applications. The UWB pulse is in these cases delivered by specific antennas whom design is compatible with the high amplitude ultrashort complex UWB radiation pulses [31]. Such equipment is mainly related to medical devices in the civilian area and to certain kind of radar in the military domain. The Kentech amplifier and Koshelev antenna used in the present work were efficient to deliver a UWB radiation pulse with a waveform comparable in amplitude and duration to that observed through the use of direct (contact) electrodes (Figure 2).

It has long been demonstrated using immersed electrode that UWB pulses induce the formation of pores (electroporation) in the plasma membrane, and that their number, size, density and duration are proportional to the pulses amplitude and duration [17]-[19] [32]. These pores life is sufficient to allow molecules of diverse size to move across the cell membranes, thus giving the opportunity to highly polar molecules to rapidly and efficiently exit the cell because of the favorable concentration gradient. Among the whole set of cellular molecules that may exit the cell, ATP received a considerable attention these last years [33]. This molecule, present in low quantity in the cell, is continuously consumed and reformed. In addition to its well known function as an energyrelated molecule, ATP is also acting as a signal molecule in both animal [25] and plant cell [34] when externalized after various kinds of environmental signals or injurious stimulus.

Here we observed that short exposure to radiated UWB radiation pulses evoke the rapid increase of ATP in the culture medium (Figure 3(A)), concomitantly with a decrease of both cellular ATP (Figure 4) and AEC (Table 1), demonstrating the cellular origin of ATP. This increase is maximum (5-fold over the control) after 15 min. Its amplitude is, however, much lower than that observed after a massive hypotonic shock (Figure 3(B), 15-fold increase) showing that only about one third to the half of the cellular ATP readily exit the cell after UWB radiation. This observation is consistent with the internal decrease (about the half) of the ATP content after UWB exposure (Figure 4).

The kinetics of ATP externalization (maximal after $15 \mathrm{~min}$ ) is consistent with the observation of Pakhomov et al. [21] [22] that reported long lasting (minutes) increased of membrane conductance of mammalian cells. The contribution of exocytosis to the ATP release, if any, remains to be proven even if short (10 min) $900 \mathrm{MHz}$ phone-type radiation increase exocytosis on epidermal Merkel cells [35]. Membrane resealing is required to preserve cell viability [17] and appears to be ATP-dependant. Reference [36] brings evidence suggesting that RF modulation in the UWB pulse, as applied in our experiments, protect the cell from a lethal electroporation and 
therefore preserves their viability. However, it is not clear if electroporation is the unique way to externalize ATP since previous work have demonstrated that ATP release from cell may involve a mechano sensitive ATP channel [37] [38]. Indeed, cell treatment with gadolinium ( $\mathrm{Gd}^{3+}$, a potent inhibitor of stretch-activated channels) prevents ATP release after hypotonic stress [39]. Furthermore, [27] demonstrated that gadolinium blocked the membrane permeabilization induced by UWB treatment in cultured cells. Taken together, these observations suggest that similar ATP channels may account, at least partially, for the ATP externalization evoked after UWB surge through specific mechanosensitive channels. It may also explain that a substantial part of ATP actually remains in the cell while a pore-driven ATP exit may have cause a more massive exit. Further experiment would be necessary to decipher if either electroporation or mechanosensitive channels or both are involved in the externalization of ATP.

The eATP concentration started to diminish after $30 \mathrm{~min}$ (Figure 3), suggesting that it was either hydrolyzed or involved (consumed) into metabolic processes. Further experiments would be required to decipher if eATP is actually involved in physiological events surrounding cell death or recovery after UWB surge. Concomitantly to the ATP release, the energy charge of the cell dropped from 0.73 (control, unexposed cells) to 0.58 in the exposed cells (Table 1), highlighting a potential strong impact of the UWB radiation exposure on the energy metabolism. Similar observations have previously been reported in plants after high frequency $(900 \mathrm{MHz})$, mobile phone-like exposure [30] and were proposed to be related to direct externalization of ATP [40].

Surprisingly, and despite deep impact on the energy metabolism of the cells, the UWB radiation pulse did not dramatically affect cells viability (Table 1). The UWB pulses used in the present work only slightly affect cell survival. Our observations are in accordance with those of reference [9] that reported that only non-fixed cultured cells are sensitive to UWB radiations. Thus, a substantial amount of ATP (Figure 4) and ATP synthesis capacity seems to be preserved in the exposed samples to allow cell survival and subsequent cell divisions. In contrast, UWB radiation pulses significantly inhibit clonogenicity by about 20\% (Table 1). This effect could be mimicked by the addition of the ATP agonist bzATP in the culture medium (Table 1) indicating that the clonogenic inhibition was indeed directly related to the ATP release, therefore suggesting that eATP was a biologically active molecule. This observation is consistent with previous work [41] [42] that highlight an inhibitory effect of ATP on cell proliferation.

\section{Conclusion}

In summary, our results demonstrated that radiated UWB pulses can effectively evoke distant biological events (rapid, massive yet non-lethal release of ATP) similarly to that observed after direct, contact electrode-based application of UWB.

\section{Acknowledgements}

The authors would like to gratefully acknowledge the LRC BIOEM ("Laboratoire de Recherche Conventionné” - LRC No. 002-2011-CEA DAM/Institut Pascal) for its financial support and the Pr M. Gendraud (University Blaise Pascal) for advices on ATP metabolism.

\section{References}

[1] Giri, D.V. and Tesche, F.M. (2004) Classification of Intentional Electromagnetic Environments (IEME). IEEE Transactions on Electromagnetic Compatibility, 46, 322-328. http://dx.doi.org/10.1109/TEMC.2004.831819

[2] Markov, M.S. (2007) Expanding Use of Pulsed Electromagnetic Field Therapie. Electromagnetic Biology and Medicine, 26, 257-274. http://dx.doi.org/10.1080/15368370701580806

[3] Nuccitelli, R., Pliquett, U., Chen, X., Ford, W., Swanson, R.J., Beebe, S.J., Kolb, J.F. and Schoenbach, K.H. (2006) Nanosecond Pulsed Electric Fields Cause Melanomas to Self-Destruct. Biochemical and Biophysical Research Communications, 343, 351-360. http://dx.doi.org/10.1016/j.bbrc.2006.02.181

[4] Breton, M. and Mir, L. (2012) Microsecond and Nanosecond Electric Pulses in Cancer Treatments. Bioelectromagnetics, 33, 106-123. http://dx.doi.org/10.1002/bem.20692

[5] Camera, F., Paffi, A., Merla, C., Denzi, A., Apollonio, F., Marracino, P., d’Inzeo, G. and Liberti, M. (2012) Effects of Nanosecond Pulsed Electric Fields on the Activity of a Hodgkin and Huxley Neuron Model. Annual International Conference of the IEEE Engineering in Medicine and Biology Society (EMBC), San Diego, 28 August-1 September 2012, 2567-2570. http://dx.doi.org/10.1109/EMBC.2012.6346488 
[6] Zito, D., Pepe, D., Mincica, M. and Zito, F. (2011) A 90nm CMOS SoC UWB Pulse Radar for Respiratory Rate Monitoring. IEEE International Solid-State Circuits Conference Digest of Technical Papers (ISSCC), San Francisco, 20-24 February 2011, 40-41.

[7] Deng, J., Schoenbach, K., Buescher, S., Hair, P., Fox, P. and Beebe, S. (2003) The Effects of Intense Submicrosecond Electrical Pulses on Cells. Biophysical Journal, 84, 2709-2714. http://dx.doi.org/10.1016/S0006-3495(03)75076-0

[8] Huang, F., Fang, Z., Mast, J. and Chen, W. (2013) Comparison of Membrane Electroporation and Protein Denature in Response to Pulsed Electric Field with Different Durations. Bioelectromagnetics, 34, 253-263. http://dx.doi.org/10.1002/bem.21773

[9] Stacey, M., Stickley, J., Fox, P., Statler, V., Schoenbach, K., Beebe, S.J. and Buescher, S. (2003) Differential Effects in Cells Exposed to Ultra-Short, High Intensity Electric Fields: Cell Survival, DNA Damage, and Cell Cycle Analysis. Mutation Research, 542, 65-75. http://dx.doi.org/10.1016/j.mrgentox.2003.08.006

[10] Beebe, S.J., Fox, P.M., Rec, L.J., Willis, L.K. and Schoenbach, K.H. (2003) Nanosecond, High-Intensity Pulsed Electric Fields Induce Apoptosis in Human Cells. FASEB Journal, 17, 1493-1495.

[11] Vernier, P.T., Sun, Y., Marcu, L., Salemi, S., Craft, C.M. and Gundersen, M.A. (2003) Calcium Bursts Induced by Nanosecond Electric Pulses. Biochemical and Biophysical Research Communications, 310, 286-295. http://dx.doi.org/10.1016/j.bbrc.2003.08.140

[12] Sylvester, P.W., Shah, S.J., Haynie, D.T. and Briski, K.P. (2005) Effects of Ultra-Wideband Electromagnetic Pulses on Pre-Neoplastic Mammary Epithelial Cell Proliferation. Cell Proliferation, 38, 153-163. http://dx.doi.org/10.1111/j.1365-2184.2005.00340.x

[13] Dorsey, W.C., Ford, B.D., Roane, L., Haynie, D.T. and Tchounwou, P.B. (2005) Induced Mitogenic Activity in AML12 Mouse Hepatocytes Exposed to Low-Dose Ultra-Wideband Electromagnetic Radiation. International Journal of Environmental Research and Public Health, 2, 24-30. http://dx.doi.org/10.3390/ijerph2005010024

[14] Chen, N., Schoenbach, K.H., Kolb, J.F., Swanson, R.J., Garner, A.L., Yang, J., Joshi, R.P. and Beebe, S.J. (2004) Leukemic Cell Intracellular Responses to Nanosecond Electric Fields. Biochemical and Biophysical Research Communications, 317, 421-427. http://dx.doi.org/10.1016/j.bbrc.2004.03.063

[15] Xiao, D., Yao, C., Liu, H., Li, C., Cheng, J., Guo, F. and Tang, L. (2013) Irreversible Electroporation and Apoptosis in Human Liver Cancer Cells Induced by Nanosecond Electric Pulses. Bioelectromagnetics, 34, 512-520.

[16] Kolb, J.F., Kono, S. and Schoenbach, K.H. (2006) Nanosecond Pulsed Electric Field Generators for the Study of Subcellular Effects. Bioelectromagnetics, 27, 172-187. http://dx.doi.org/10.1002/bem.20185

[17] Rols, M.P., Delteil, C., Golzio, M. and Teissié, J. (1998) Control by ATP and ADP of Voltage-Induced MammalianCell-Membrane Permeabilization, Gene Transfer and Resulting Expression. European Journal of Biochemistry, 254, 382-388. http://dx.doi.org/10.1046/j.1432-1327.1998.2540382.x

[18] Joshi, R.P. and Schoenbach, K.H. (2000) Electroporation Dynamics in Biological Cells Subjected to Ultrafast Electrical Pulses: A Numerical Simulation Study. Physical Review E, 62, 1025-1033. http://dx.doi.org/10.1103/PhysRevE.62.1025

[19] Vasilkoski, Z., Esser, A.T., Gowrishankar, T.R. and Weaver, J.C. (2006) Membrane Electroporation: The Absolute Rate Equation and Nanosecond Time Scale Pore Creation. Physical Review E, 74, Article ID: 021904. http://dx.doi.org/10.1103/PhysRevE.74.021904

[20] Weaver, J.C. and Chizmadzhev, Y.A. (1996) Theory of Electroporation: A Review. Bioelectrochemistry and Bioenergetics, 41, 135-160. http://dx.doi.org/10.1016/S0302-4598(96)05062-3

[21] Pakhomov, A.G., Kolb, J.F., White, J.A., Joshi, R.P., Xiao, S. and Schoenbach, K.H. (2007) Long-Lasting Plasma Membrane Permeabilization in Mammalian Cells by Nanosecond Pulsed Electric Field (nsPEF). Bioelectromagnetics, 28, 655-663. http://dx.doi.org/10.1002/bem.20354

[22] Pakhomov, A.G., Shevin, R., White, J.A., Kolb, J.F., Pakhomova, O.N., Joshi, R.P. and Schoenbach, K.H. (2007) Membrane Permeabilization and Cell Damage by Ultrashort Electric Field Shocks. Archives of Biochemistry and Biophysics, 465, 109-118. http://dx.doi.org/10.1016/j.abb.2007.05.003

[23] Pavlin, M., Kotnik, T., Miklavc, D., Kramar, P. and Lebar, A.M. (2008) Electroporation of Planar Lipid Bilayers and Membranes. In: Liu, L., Ed., Advances in Planar Lipid Bilayers and Liposomes, Vol. 6, Chapter 7, Elsevier B.V Academic Press, London, 165-226.

[24] Rols, M.P. and Teissié, J. (1990) Electropermeabilization of Mammalian Cells. Quantitative Analysis of the Phenomenon. Biophysical Journal, 58, 1089-1098. http://dx.doi.org/10.1016/S0006-3495(90)82451-6

[25] Nowak, I. (2003) ATP as a Signaling Molecule: The Exocrine Focus. Physiology, 18, 12-17.

[26] Sauer, H., Stanelle, R., Hescheler, J. and Wartenberg, M. (2002) The DC Electrical-Field-Induced Ca ${ }^{2+}$ Response and $^{2}$ Growth Stimulation of Multicellular Tumor Spheroids Are Mediated by ATP Release and Purinergic Receptor Stimu- 
lation. Journal of Cell Science, 115, 3265-3273.

[27] André, F.M., Rassokhin, M.A., Bowman, A.M. and Pakhomov, A.G. (2010) Gadolinium Blocks Membrane Permeabilization Induced by Nanosecond Electric Pulses and Reduces Cell Death. Bioelectrochemistry, 79, 95-100. http://dx.doi.org/10.1016/j.bioelechem.2009.12.007

[28] Koshelev, V.I., Buyanov, Y.I., Andreev, Y.A., Plisko, V.V. and Sukhushin, K.N. (2001) Ultrawideband Radiators of High-Power Pulses. Proceedings of the IEEE Pulsed Power Plasma Science Conference, 2, 1661-1667.

[29] Cadilhon, B., Cassany, B., Modin, P., Diot, J.C., Bertrand, V. and Pécastaing, L. (2011) Ultra Wideband Antennas for High Pulsed Power Applications. In: Matin, M., Ed., Ultra Wideband Communications: Novel Trends-Antennas and Propagation, InTech, Rijeka, Croatia, 277-306.

[30] Roux, D., Vian, A., Girard, S., Bonnet, P., Paladian, F., Davies, E. and Ledoigt, G. (2008) High Frequency (900 MHz) Low Amplitude $\left(5 \mathrm{Vm}^{-1}\right)$ Electromagnetic Field: A Genuine Environmental Stimulus that Affects Transcription, Translation, Calcium and Energy Charge in Tomato. Planta, 227, 883-891. http://dx.doi.org/10.1007/s00425-007-0664-2

[31] Godard, A., Desrumaux, L., Bertrand, V., Andrieu, J., Lalande, M., Jecko, B., Brishoual, M., Couderc, V. and Guillerey, R. (2010) A Transient UWB Antenna Array Used with Complex Impedance Surfaces. International Journal of Antennas and Propagation, 2010, Article ID: 243145. http://dx.doi.org/10.1155/2010/243145

[32] Bennett, L.I., Mixon, D.G., Payne, A.B., Bowman, A., Sickendick, K., Wilmink, G.J., Roach, W.P. and Pakhomov, A.G. (2010) Plasma Membrane Permeabilization by Trains of Ultrashort Electric Pulses. Bioelectrochemistry, 79, 114-121. http://dx.doi.org/10.1016/j.bioelechem.2010.01.001

[33] Vitiello, L., Gorini, S., Rosano, G. and la Sala, A. (2012) Immunoregulation through Extracellular Nucleotides. Blood, 120, 511-518. http://dx.doi.org/10.1182/blood-2012-01-406496

[34] Tanaka, K., Gilroy, S., Jones, A.M. and Stacey, G. (2010) Extracellular ATP Signaling in Plants. Trends Cell Biol., 20, 601-608.

[35] Irmak, K.M., Oztas, E., Yagmurca, M., Fadillioglu, E. and Bakir, B. (2003) Effects of Electromagnetic Radiation from a Cellular Telephone on Epidermal Merkel Cells. Journal of Cutaneous Pathology, 30, 135-138. http://dx.doi.org/10.1046/j.0303-6987.2003.00002.x

[36] Jordan, D.W., Gilgenbach, R.M., Uhler, M.D., Gates, L.H. and Lau, Y.Y. (2004) Effect of Pulsed, High-Power Radiofrequency Radiation on Electroporation of Mammalian Cells. IEEE Transactions on Plasma Science, 32, 1573-1578.

[37] Braunstein, G.M., Roman, R.M., Clancy, J.P., Kudlow, B.A., Taylor, A.L., Shylonsky, V.G., Jovov, B., Peter, K., Jilling, T., Ismailov, I.I., Benos, D.J., Schwiebert, L.M., Fitz, J.G. and Schwiebert, E.M. (2001) Cystic Fibrosis Transmembrane Conductance Regulator Facilitates ATP Release by Stimulating a Separate ATP Release Channel for Autocrine Control of Cell Volume Regulation. Journal of Biological Chemistry, 276, 6621-6630. http://dx.doi.org/10.1074/jbc.M005893200

[38] Bao, L., Locovei, S. and Dahl, G. (2004) Pannexin Membrane Channels Are Mechanosensitive Conduits for ATP. FEBS Letters, 572, 65-68. http://dx.doi.org/10.1016/j.febslet.2004.07.009

[39] Boudreault, F. and Grygorczyk, R. (2002) Cell Swelling-Induced ATP Release and Gadolinium-Sensitive Channels. American Journal of Physiology-Cell Physiology, 282, 219-226. http://dx.doi.org/10.1152/ajpcell.00317.2001

[40] Roux, D., Faure, C., Bonnet, P., Girard, S., Ledoigt, G., Davies, E., Gendraud, M., Paladian, F. and Vian, A. (2008) A Possible Role for Extra-Cellular ATP in Plant Responses to High Frequency, Low Amplitude Electromagnetic Field. Plant Signaling \& Behavior, 3, 383-385. http://dx.doi.org/10.4161/psb.3.6.5385

[41] Janssens, R. and Boeynaems, J.M. (2001) Effect of Extracellular Nucleotides and Nucleoside on Prostate Carcinoma Cells. British Journal of Pharmacology, 132, 536-546. http://dx.doi.org/10.1038/sj.bjp.0703833

[42] Fang, W.G., Pirnia, F., Bang, Y.J., Myers, C.E. and Trepel, J.B. (1992) P2-Purinergic Receptor Agonists Inhibit the Growth of Androgen-Independent Prostate Carcinoma Cells. Journal of Clinical Investigation, 89, 191-196. http://dx.doi.org/10.1172/JCI115562 